\title{
Avaliação da Aplicabilidade da Técnica de Maturação in vitro de Oócitos Humanos e Posterior Fertilização
}

\author{
Evaluation of the Usefulness of the in vitro Maturation \\ Technique of Human Oocyte and Subsequent Fertilization \\ Maria Clara Magalhães dos Santos Amaral ${ }^{1}$, \\ Maria das Graças Rocha Santana Camargos ${ }^{1}$, \\ Marco Aurélio Fernandes Vieira ${ }^{1}$, Rubens Lene Carvalho Tavares ${ }^{1}$, \\ Claudia Navarro Carvalho Duarte Lemos ${ }^{1}$, Aroldo Fernando Camargos ${ }^{2}$
}

\begin{abstract}
RESUMO
Objetivos: avaliar a aplicabilidade da técnica de maturação in vitro de oócitos humanos e posterior fertilização.

Métodos: estudo prospectivo não randomizado descritivo realizado no período de novembro de 1999 a março de 2001 no qual foram incluídas 15 pacientes com infertilidade tubária e 20 ciclos de fertilização in vitro. Todas assinaram o termo de consentimento livre e esclarecido antes de iniciar o estudo. As pacientes tinham idade entre 18 e 32 anos incompletos, obstrução tubária como causa exclusiva de infertilidade e índice de massa corporal inferior a $25 \mathrm{~kg} /$ $\mathrm{m}^{2}$. As pacientes receberam 300 UI de hormônio foliculo estimulante (FSH) recombinante por via intramuscular no segundo dia do ciclo e doses adicionais de 150 UI no quarto e no sexto dia do ciclo. A coleta ovular foi realizada no sétimo dia do ciclo. Os oócitos foram colocados em meio TCM 199 acrescido de antibióticos, piruvato, FSH, gonadotrofina coriônica humana e soro (Serum Substitute Supplement - Irvine Scientific ${ }^{\circledR}$ ). Após 48 h de cultivo, os oócitos que atingiram o estágio de metáfase II foram inseminados e os fertilizados foram transferidos. Resultados: foram puncionados 144 folículos com a coleta de 67 oócitos imaturos (46,5\%). Quarenta e três oócitos atingiram o estágio de metáfase II $(64,2 \%)$ e foram inseminados. Destes, 30 fertilizaram e 25 embrióes foram transferidos para 10 pacientes. Houve uma gravidez com nascimento de um bebê.

Conclusão: concluiu-se que a técnica de maturar oócitos humanos in vitro previamente à fertilização in vitro é técnica exeqüivel, capaz de gerar gravidez.
\end{abstract}

PALAVRAS-CHAVE: Fertilização in vitro. Infertilidade.

\section{Introdução}

Em 1939, Pincus e Saunders ${ }^{1}$, pesquisando óocitos humanos obtidos por aspiração folicular de folículos excisados, observaram o início do proces-

${ }^{1}$ Laboratório de Reprodução Humana do Hospital das Clínicas da UFMG

${ }^{2}$ Departamento de Ginecologia e Obstetrícia da Faculdade de Medicina da UFMG

Correspondência:

Maria Clara Magalhães dos Santos Amaral

Avenida Pasteur, 89/1202 - Bairro Santa Efigênia

30150-290 - Belo Horizonte - MG

e-mail: gmsamaral@yahoo.com.br so de maturação em $40 \%$ dos oócitos cultivados. Veeck et al. ${ }^{2}$, em 1983, relataram a primeira gravidez e nascimento de bebê gerado por meio da maturação in vitro de oócitos humanos. Em seguida, vários outros autores relataram gestações e nascimentos após maturação in vitro ${ }^{3-5}$, inclusive gravidez trigemelar ${ }^{6}$.

Após 1992 a maioria dos trabalhos com maturação in vitro passou a utilizar a injeção intracitoplasmática de espermatozóides (ICSI), acreditando-se em melhores resultados com a ICSI ou para diminuir viés na presença de fator masculino ${ }^{4}$. A coleta de oócitos imaturos in vivo guiada por ultra-sonografia ou por via laparoscópica ini- 
ciou-se em $1994^{3}$ e, até 1998, pouco mais de 10 bebês haviam nascido em todo o mundo, frutos de oócitos maturados in vitro e posteriormente fertilizados, o que revela baixíssimas taxas de sucesso ${ }^{7}$.

A literatura é controversa sobre a necessidade de estimulação prévia com $\mathrm{FSH}$ para otimizar os esquemas de maturação in vitro ${ }^{8}$. Há relato de gestações bem sucedidas após ciclos sem utilização prévia de gonadotrofina ${ }^{9}$, enquanto outros artigos demonstram melhores taxas de maturação nuclear $^{10}$ ou de maturação citoplasmática ${ }^{11}$ em oócitos extraídos de ovários estimulados.

Um sistema de cultivo ideal para a maturação in vitro ${ }^{8}$ deveria prover os substratos necessários para a maturação oocitária nos momentos exatos, como ocorre no folículo pré-ovulatório in vivo ${ }^{7}$. Hoje existem vários meios de cultivo de oócito, sendo difícil comparação de eficácia entre os mesmos. Há pesquisas com substâncias adicionadas ao meio de cultivo, como componentes protéicos, substratos energéticos e nutrientes ${ }^{12,13}$; adição de hormônios ${ }^{12,14}$; fatores de crescimento ou substâncias afins e modelos de cultivo ${ }^{6}$; adição de fluido folicular ao meio de cultivo ${ }^{6,15}$.

Com o objetivo de diminuir efeitos inibitórios em funções das células da granulosa surgiram sistemas sem a adição de soros (meios serum free). Meios serum free foram associados a uma combinação de insulina e análogo sintético LongR3 IGF para humanos em concentrações baseadas nos niveis de insulina e fator de crescimento insulina-símile - I (IGF-I) medidos em folículos antrais humanos ${ }^{11}$.

A literatura revela que maior concentração sérica de estradiol e inibina A no terceiro dia do ciclo e no dia da coleta ovular correlaciona-se com melhores taxas de gravidez em pacientes não estimuladas submetidas à maturação in vitro de oócitos $^{16}$. O nível de FSH encontrado no terceiro dia do ciclo tem correlação negativa com o número de oócitos captados ${ }^{17}$, e menor concentração de estradiol no terceiro dia do ciclo está relacionada a taxas de gravidez significativamente superiores, quando comparadas às pacientes com niveis altos ${ }^{17,18}$.

A literatura revela também maior taxa de recuperação e de maturação de oócitos em pacientes jovens e maior taxa de apoptose em pacientes com mais de 41 anos $^{19}$. Pacientes com síndrome do ovário policístico apresentam decréscimo nas taxas de maturação quando comparadas a oócitos de ovários normais. A porcentagem de oócitos degenerados na sindrome do ovário policístico é superior à das mulheres normais ${ }^{6,7}$. Há menor habilidade para o desenvolvimento e maturação ${ }^{20} \mathrm{e}$ menor taxa de fecundação por ciclo e maior taxa de abortos $^{21}$.
O objetivo do presente trabalho foi avaliar a aplicabilidade da técnica de maturação in vitro de oócitos humanos e posterior fertilização.

\section{Pacientes e Métodos}

Trata-se de estudo prospectivo, não randomizado, descritivo, em que foram avaliados 20 ciclos em 15 pacientes oriundas do Setor de Reprodução Humana do Hospital das Clínicas da Universidade Federal de Minas Gerais e do PAM Sagrada Família em Belo Horizonte. Os ciclos foram realizados de novembro de 1999 a março de 2001. O protocolo do estudo foi aprovado pelo colegiado do curso de pós-graduação em Ginecologia e Obstetrícia.

Os critérios de inclusão foram idade entre 18 e 32 anos incompletos; obstrução tubária como causa exclusiva de infertilidade; indicação para maturação in vitro (FIV); impossibilidade de execução de ciclos de FIV convencionais; ciclos menstruais regulares; assinatura do termo de consentimento livre e esclarecido. Os critérios de exclusão foram presença de outra causa de infertilidade que não a obstrução tubária; índice de massa corporal superior a $25 \mathrm{~kg} / \mathrm{m}^{2}$; análise seminal do parceiro alterada; niveis séricos de FSH no terceiro dia do ciclo superiores a $15 \mathrm{UI} / \mathrm{ml}$; presença de doença intracavitária (intra-uterina) diagnosticada por histeroscopia diagnóstica ou de doença que contra-indicasse a gestação ou levasse a uma gestação de risco.

A média de idade foi de 27,5 anos $( \pm 2,7)$. A média do índice de massa corporal foi de $23,2 \mathrm{~kg} / \mathrm{m}^{2}$ $( \pm 1,5)$. A duração média da infertilidade foi de 5,4 anos $( \pm 3,0)$.

As pacientes fizeram uso de 300 UI de FSH recombinante (Gonal- $\mathrm{F}^{\circledR}$ Serono) intramuscular, no segundo dia do ciclo (sendo o primeiro dia do ciclo definido como o primeiro dia de sangramento) e doses adicionais de 150 UI no quarto e no sexto dia do ciclo. Realizaram-se duas ultra-sonografias transvaginais com sonda de $5 \mathrm{MHz}$ (Aloka SSD500), a primeira no segundo dia do ciclo, para que se excluísse a presença de algum cisto ovariano, e a segunda no sexto dia do ciclo, para acompanhamento do desenvolvimento folicular e endometrial. A coleta ovular foi realizada invariavelmente no sétimo dia do ciclo.

Para a coleta ovular foi feito anestesia paracervical com xilocaína a $2 \%$ com adrenalina. Utilizamos agulhas de calibre 16, lúmen duplo (Cook), guiadas por ultra-sonografia endovaginal (Aloka SSD-500). Essas agulhas foram lavadas previamente com meio de cultivo heparinizado 
para diminuição do espaço morto e aquecimento das mesmas (Dulbecco's Phosphate-Buffered Saline - 9,6 g/L - Sigma), acrescido de 0,003 g de heparina (50000 UI - Sigma - H 3149), 0,075 g de penicilina G (10.000.000 UI - Sigma - P 4687) e $1 \mathrm{~mL}$ de gentamicina ( $10 \mathrm{mg} / \mathrm{mL}$ - Sigma - G 1272) a $37^{\circ} \mathrm{C}$, pH entre $7,3 \pm 0,3$ e osmolaridade entre 288 $\pm 5 \mathrm{mOsm} / \mathrm{L}$. Utilizou-se bomba de sucção com pressão negativa (Craft Suction Unit - Rocket Medical), com pressão de aspiração fixa de 80 mmHg. Após a aspiração do líquido folicular, o folículo foi lavado com $0,1 \mathrm{~mL}$ do mesmo meio e novamente aspirado.

O líquido folicular foi transferido para placas de Petri (100 mm x 20 mm, Corning) para identificação dos complexos cumulus-oócito em lupa (Nikon SMZ-2T) e em microscópio óptico invertido (Zeiss - Telaval 31). Os oócitos foram classificados como imaturos segundo os seguintes critérios de Veeck et al. (1983) ${ }^{2}$. Resumidamente, estes autores classificam as células da granulosa como compactas ou firmemente aderidas; as células do cumulus como ausentes ou presentes ou densas; a corona como compacta ou ausente, e o ooplasma como escurecido ou com presença de vesícula germinal.

Os oócitos imaturos foram transferidos para as placas de Nunc (Multidish 4 wells - Nunc Brand Products), um a dois por poço, com $6 \mathrm{~mL}$ de meio de maturação específico divididos em $1 \mathrm{~mL}$ para cada poço e $2 \mathrm{~mL}$ no meio da placa. As placas foram preparadas sempre com um dia de antecedência, acrescentando-se soro (Serum Substitute Supplement - Irvine Scientific ${ }^{\circledR}$ ) ao meio de maturação em concentração final na placa de $4 \%$ $(0,4 \mathrm{~mL}$ de soro $+9,6 \mathrm{~mL}$ do meio). As placas foram então transferidas para estufas de $\mathrm{CO}_{2}$ (Forma Scientific CO2 Water Jacket Incubator) à temperatura de $37^{\circ} \mathrm{C}$ e fluxo de $\mathrm{CO}_{2}$ a $5 \%$ para equilibrar a temperatura e o $\mathrm{pH}$.

O meio de maturação foi constituído de $100 \mathrm{~mL}$ de TCM 199 (Tissue Culture Medium 199 - Sigma M 4530), acrescido de $0,1 \mathrm{ml}$ de piruvato de sódio (11 mg/mL - Sigma - S 8636), 0,006 g penicilina G (Sigma), 0,1 mL de gentamicina (Sigma), 0,075 UI/ $\mathrm{m}$ L de FSH recom binante $G$ ona $\mathbb{F}^{\circledR}$ - Serono) e 0,5 $\mathrm{UI} / \mathrm{ml}$ de hCG (Profasi ${ }^{\circledR}$ - Serono). O pH do meio oscilava entre $7,3 \pm 0,3$ (medido por medidor de $\mathrm{pH}$ Digimed, modelo DMPH-2) e a osmolaridade oscilava entre $288 \pm 5 m$ Osm/L (medido por Osmeet Micro Osmometer).

Os oócitos imaturos permaneceram incubados no meio, nas placas de Nunc, por período de 48 horas, após o que foram graduados como: prófase I (ausência de maturação), metáfase I (MI), metáfase II (MII) ou degenerados. Os oócitos em MII foram então transferidos para placas de Nunc com $6 \mathrm{~mL}$ de meio apenas para cultivo (IVF тм20 Vitrolife) distribuídos da mesma forma que o meio de maturação: $1 \mathrm{~mL}$ por poço e $2 \mathrm{~mL}$ no centro da placa. Essas placas também foram preparadas com um dia de antecedência para estabilização prévia (da temperatura e $\mathrm{pH}$ ) em estufas de $\mathrm{CO}_{2}$ (Forma Scientific - Water Jacket Incubator) com fluxo de $\mathrm{CO}_{2}$ a $5 \%$ e $37^{\circ} \mathrm{C}$. Os oócitos (em MII) foram então submetidos à inseminação. Realizou-se beneficiamento do sêmen com a técnica de swim-up, na qual, resumidamente, o sêmen é depositado em tubo de 15 $\mathrm{mL}$ (Falcon-Corning) estéril junto com o dobro do volume de Dulbecco's PBS e homogeneíza-se. Centrifuga-se a 300 g por 10 minutos. Descarta-se o sobrenadante e torna-se a suspender o pellet com mais $2 \mathrm{~mL}$ de PBS. Centrifuga-se por mais cinco minutos a $300 \mathrm{~g}$. Despreza-se novamente o sobrenadante e torna-se a suspender o pellet com 1 mL de IVF TM20 Vitrolife. Centrifuga-se por mais três minutos e coloca-se em tubo de ensaio estéril em estufa de $\mathrm{CO}_{2}\left(37^{\circ} \mathrm{C}\right)$, com uma angulação de cerca de $45^{\circ}$, em repouso, para que os espermatozóides migrem por cerca de 40 a 45 minutos. Retira-se o sobrenadante e despreza-se o pellet. A inseminação é realizada com o sobrenadante diluído.

O sêmen foi avaliado de acordo com diretrizes padronizadas pelo Manual de Laboratório da Organização Mundial de Saúde de $1994^{22}$. Resumidamente, um espermograma normal apresenta volume de $2,0 \mathrm{~mL}$ ou mais, $\mathrm{pH}$ entre 7,2 a 8,0, concentração espermática $\geq 20 \times 10 / \mathrm{mL}$, motilidade $\geq 50 \%$ com progressão tipo 2 e 3 ou $>25 \%$ com progressão tipo 3 nos primeiros 60 minutos, morfologia com $\geq 30 \%$ de formas normais, vitalidade com $\geq 75 \%$ de espermatozóides vivos e contagem de leucócitos <1.000.000/mL.

Cerca de 18 horas após a inseminação, pesquisou-se por microscopia óptica a presença dos pró-núcleos, indicando fertilização. No segundo dia após a inseminação, observou-se o desenvolvimento embrionário. Esses, se clivados, eram classificados e então transferidos para o interior da cavidade uterina. A classificação dos embriões foi realizada de acordo com os critérios de Van Steirteghem et al. ${ }^{23}$, quanto ao nivel de fragmentação: tipo A (sem fragmentos), tipo B (1 a 20\% de fragmentos), tipo C (20 a 50\% de fragmentação) e tipo D (>50\% de fragmentação).

A transferência de embrião foi realizada com cateter tom cat (Cook) estéril, sendo introduzido até uma distância $1 \mathrm{~cm}$ menor que a medida da cavidade uterina, medida previamente por ultrasonografia endovaginal. Os embriões foram transferidos juntamente com $25 \mu 1$ de meio de cultivo da placa IVF-тм20 (Vitrolife).

Desde o dia da coleta ovular, as pacientes iniciaram a preparação do endométrio com $17 \beta$ 
estradiol (Estrofen ${ }^{\circledR-}$ Medley), $2 \mathrm{mg}$ de oito em oito horas por via oral. Após 48 horas da coleta, foi acrescentada ao estradiol a progesterona micronizada (Utrogestan ${ }^{\circledR}$ - Enila), 200 mg, também de oito em oito horas, em forma de comprimidos administrados por via vaginal. Essa medicação foi mantida até 12 dias após a transferência embrionária, quando a paciente realizava o exame de gravidez ( $\beta$ hCG). Em caso de gravidez a progesterona foi mantida até a $12^{\mathrm{a}}$ semana de gestação. Foi definida como gravidez clínica a presença de atividade cardíaca embrionária intra-uterina após cinco semanas de transferência embrionária por meio de ultra-sonografia endovaginal.

Foi realizada análise descritiva das varáveis utilizando-se o programa Epi-Info versão 6.04. Admitiu-se como diferença estatisticamente significativa quando presente um valor $\mathrm{p}<0,05$.

\section{Resultados}

Foram realizados 20 ciclos com 19 coletas ovulares (Tabela 1). Um ciclo foi cancelado devido à inacessibilidade do ovário. Foram puncionados 144 folículos com média de 7,6 folículos por paciente (variando de três a 27). Foram coletados 67 oócitos (taxa de captação de $46,5 \%$ por folículo puncionado), com média de 3,5 oócitos por coleta (variando de zero a oito).

Tabela 1 - Captação, maturação, fertilização, desenvolvimento embrionário e taxas de gravidez obtidas de oócitos humanos maturados in vitro.

\begin{tabular}{|c|c|c|c|c|}
\hline Variáveis & Número & $\%$ & $I C^{1} \mathrm{a}$ & a $95 \%$ \\
\hline Ciclos & 19 & - & & - \\
\hline Folículos puncionados & 144 & - & & - \\
\hline Oócitos captados & 67 & $46,5 \%$ & 38,2 & a 55,0 \\
\hline Ml após $48 h^{2}$ & 3 & $4,5 \%$ & 1,2 & a 13,4 \\
\hline MII após $48 \mathrm{~h}^{3}$ & 43 & $64,2 \%$ & 51,5 & a 75,2 \\
\hline Oócitos fertilizados & 30 & $69,8 \%$ & 53,7 & a 82,3 \\
\hline $\begin{array}{l}\text { Embriões clivados e } \\
\text { transferidos }\end{array}$ & 25 & $83,3 \%$ & 64,5 & a 93,7 \\
\hline Gravidez & $1 / 10$ & $10 \%$ & 0,5 & a 45,9 \\
\hline Implantação & $1 / 25$ & $4 \%$ & 0,2 & a 22,3 \\
\hline Bebê em casa & $1 / 10$ & $10 \%$ & 0,5 & a 45,9 \\
\hline
\end{tabular}

${ }^{1} \mathrm{C}$ - Intervalo de confiança

${ }^{2} \mathrm{Ml}$ - Oócito em metáfase I

${ }^{3} \mathrm{MII}$ - Oócito em metáfase II

Após 48 horas de cultivo, nove oócitos degeneraram (13,4\%), 12 permaneceram em prófase I (17,9\%), três atingiram o estágio de MI $(4,5 \%)$ e 43 atingiram o estágio de MII (64,2\%). Dos 43 oócitos inseminados, 30 foram fertilizados $(69,8 \%)$. Hou- ve clivagem em 25 embriões $(83,3 \%)$ e foram transferidos ao longo de 10 ciclos. Houve uma gravidez com nascimento de bebê saudável (5,3\% de gravidez por coleta ovular e 10\% por transferência). A taxa de implantação foi de 4\% (1/25) (Tabela 1).

Dos 25 embriões transferidos, quatro (16\%) foram do tipo A, nove (36\%) tipo B e 12 (48\%) do tipo C, segundo os critérios de Van Steirteghem et al. ${ }^{23}$ descritos anteriormente.

Foi realizada uma simples comparação entre as diferentes épocas de realização do estudo, as quais foram setembro de 1999, março e abril de 2000 e março de 2001 Compararam-se as taxas de maturação e fertilização pelo do teste do $\chi^{2}$. Encontrou-se valor $\mathrm{p}=0,0155$ para os resultados de maturação e valor $\mathrm{p}=0,7528$ para a fertilização para as diferentes épocas (Tabela 2).

\section{Discussão}

As 15 pacientes formaram grupo homogêneo quanto à idade, condições socioeconômicas, índice de massa corporal e causa de infertilidade. O valor médio de 3,5 oócitos por coleta foi inferior ao de alguns autores que utilizaram técnica similar (7,5 por Wynn et al. ${ }^{8}$ e 5,6 por Chian et al..$^{5}$, mas superior ao de Thornton et al..$^{9}(0,7)$ e muito similares aos de Mikkelsen et al. ${ }^{16}$, com e sem estímulo mínimo com FSH prévio (4,0 com FSH e 3,7 sem FSH).

A necessidade do uso de FSH em pequenas doses para se obterem melhores resultados com maturação in vitro de oócitos é controversa. Existem artigos com resultados superiores quando se usa a estimulação ovariana prévia com $\mathrm{FSH}^{8}$, mas há trabalhos sem uso do estímulo ovariano demonstrando taxas similares às encontradas com o estímulo ovariano mínimo ${ }^{16,24}$.

A taxa de maturação de 64,2\% (43 dos 67 oócitos coletados) foi superior ou similar às encontradas por Cha et al. ${ }^{6}(55,8$ e $35,9 \%$, respectivamente com adição de fluido folicular e soro de cordão) e por Trounson et al. ${ }^{3}$ (54,8\%). Contudo, estudo mais recente mostrou taxa de maturação superior $(85 \%)^{16}$. Essa superioridade talvez se deva à casuística mais expressiva e, provavelmente, maior familiaridade com a técnica.

O presente trabalho foi realizado com FIV e a taxa de fertilização encontrada $(69,8 \%)$ foi similar aos dados relatados por Cha et al. ${ }^{6}(81$ e $31,5 \%$, respectivamente, dos oócitos maturados com a adição de fluido folicular e soro de cordão aos meios de maturação), Trounson et al. ${ }^{3}$ (22,9\% no primeiro experimento e $40,75 \%$ no segundo experimento) e Smith et al. ${ }^{24}$ (média de $75 \%$ ). 
Tabela 2 - Caracterização dos ciclos por época em que foram realizados.

\begin{tabular}{lccccc}
\hline Épocas & Folículos $^{1}$ & Captação oocitária & Maturação & Fertilização & Embriões T $^{3}$ \\
\hline $11 / 1999$ & 10,5 & Média de 3,75 (34,8\%) & $33,3 \%$ & $60 \%$ & 3 \\
03 e 04/2000 & 8,8 & Média de 3,8 (48,9\%) & $76,9 \%$ & $75 \%$ & 12 \\
$03 / 2001$ & 5,8 & Média de 5,8 (54,4\%) & $69,2 \%$ & $66,7 \%$ & 10 \\
\hline
\end{tabular}

${ }^{1}$ Folículos por paciente

${ }^{2}$ Captação oocitária por paciente

${ }^{3}$ Embriões transferidos

A taxa de gravidez por transferência de embrião (10\%) foi similar à relatada por Trounson et al. ${ }^{3}(7,6 \%)$, mas foi inferior à descrita por Thornton et al. ${ }^{9}(28 \%)$, Mikkelsen et al. ${ }^{16}(17,4 \%)$, Cha et al. $^{21}(27,1 \%)$ e Mikkelsen et al. ${ }^{17}(18 \%)$.

Apesar de não ser objetivo deste trabalho, notou-se uma tendência de melhores resultados à medida que a familiaridade com a técnica crescia: houve diferentes taxas de maturação entre as três épocas de realização do trabalho $(p=0,0155)$. No que diz respeito às taxas de fertilização, os resultados não diferiram entre as épocas $(\mathrm{p}=0,7528)$.

Não há consenso sobre quais seriam os melhores meios de cultivo e substâncias a ele adicionadas. A situação atual da maturação in vitro ainda mostra taxas de gravidez aquém das obtidas pelas técnicas convencionais FIV ou ICSI. Não foi encontrada na literatura apresentada a descrição sobre a qualidade dos embriões transferidos e, por isso, não se pôde comparar os embriões deste com os de outros trabalhos. Até a presente data, o bebê nascido em 4 de janeiro de 2001, por meio de tal técnica, se encontra saudável e apresentando desenvolvimento normal para a idade.

Pode-se concluir a partir do presente estudo que a técnica de maturar oócitos humanos in vitro previamente à FIV é técnica totalmente exeqüível, capaz de gerar gravidez. A obtenção de melhores resultados em todos os passos da maturação in vitro de oócitos seguida de FIV, ao longo do tempo de realização da pesquisa, traduz a aquisição de melhor domínio da técnica em todos os seus passos. Devido ao tamanho amostral limitado, não se pode inferir qualquer coisa além da aplicabilidade do método com o objetivo proposto neste estudo.

\section{ABSTRACT}

Purpose: to evaluate the usefulness of the in vitro maturation technique of human oocyte and subsequent fertilization. Methods: this is a prospective nonrandomized, descriptive study, carried out during the period of November 1999 to March 2001, with 20 cycles of in vitro fertilization of 15 patients with tubal infertility. All signed the written informed consent before the beginning of the study. The selected patients were at least 18 and at most 32 years of age, with only tubal infertility, and body mass index less than $25 \mathrm{~kg} /$ $\mathrm{m}^{2}$. The patients received $300 \mathrm{UI}$ of recombinant follicle stimulating hormone (FSH) by intramuscular injection at the second day of the cycle and additional doses of $150 \mathrm{IU}$ at the fourth and sixth days of cycle. The oocyte retrieval was performed at the seventh day of the cycle. Those oocytes classified as immature were cultured in tissue culture medium 199 (TCM-199) with antibiotics, pyruvate, FSH, human chorionic gonadotropin ( $h C G$ ) and serum (serum substitute supplement - Irvine Scientific $\left.{ }^{\circledR}\right)$. After 48 h of culture, the oocytes that achieved metaphase II stage were inseminated, and the fertilized ones were transferred.

Results: one hundred and forty-four follicles were aspirated. There were 67 (46.5\%) immature retrieved oocytes and 43 $(64.2 \%)$ reached the metaphase II stage and were inseminated. Thirty fertilized oocytes and 25 embryos were transferred to 10 patients. There was one pregnancy with a baby born.

Conclusion: we conclude that to mature human oocytes in vitro before in vitrofertilization is a procedure able to achieve pregnancy.

KEYWORDS: In vitrofertilization. Infertility.

\section{Referências}

1. Pincus G, Saunders B. The comparative behavior of mammalian eggs in vivo and in vitro IV. The maturation of human ovarian ova. Anat Rec 1939; 75:537-45.

2. Veeck LL, Wortham JW Jr, Witmyer J, et al. Maturation and fertilization of morphologically immature human oocytes in a program of in vitro fertilization. Fertil Steril 1983; 39:594-602.

3. Trounson A, Wood C, Kausche A. In vitro maturation and the fertilization and developmental competence of oocytes recovered from untreated polycystic ovarian patients. Fertil Steril 1994; 62:353-62.

4. Nagy ZP, Cecile J, Liu J, Loccufier A, Devroey P, Van Steirteghem A. Pregnancy and birth after intracytoplasmic sperm injection of in vitro matured germinal-vesicle stage oocytes: case report. Fertil Steril 1996; 65:1047-50. 
5. Chian RC, Buckett WM, Too LL, Tan SL. Pregnancies resulting from in vitro matured oocytes retrieved from patients with polycystic ovary syndrome after priming with human chorionic gonadotropin. Fertil Steril 1999; 72:639-42.

6. Cha KY, Koo JJ, Ko JJ, Choi DH, Han SY, Yoon TK. Pregnancy after in vitro fertilization of human follicular oocytes collected from nonstimulated cycles, their culture in vitro and their transfer in a donor oocyte program. Fertil Steril 1991; 55:109-13.

7. Moor RM, Dai Y, Lee C, Fulka J Jr. Oocyte maturation and embryonic failure. Hum Reprod Update 1998; 4:223-36.

8. Wynn P, Picton HM, Krapez JA, Rutherford AJ, Balen AH, Gosden RG. Pretreatment with follicle stimulating hormone promotes the numbers of human oocytes reaching metaphase II by in-vitro maturation. Hum Reprod 1998; 13:3132-8.

9. Thornton MH, Francis MM, Paulson RJ. Immature oocyte retrieval: lessons from unstimulated IVF cycles. Fertil Steril 1998; 70:647-50.

10.Gomez E, de los Santos MJ, Ruiz A, Tarin JJ, Remohi J, Pellicer A. Effects of epidermal growth factor in the final stages of nuclear and cytoplasmic oocyte maturation in humans. Hum Reprod 1993; 8:691-4.

11.Anderiesz C, Ferraretti A, Magli C, et al. Effect of recombinant human gonadotrophins on human, bovine and murine oocyte meiosis, fertilization and embryonic development in vitro. Hum Reprod 2000; 15:1140-8.

12.Trounson A, Anderiesz C, Jones GM, Kausche A, Lolatgis N, Wood C. Oocyte maturation. Hum Reprod 1998; 13 (Suppl 3):52-62.

13.Zheng P, Wang H, Bavister BD, Ji W. Maturation of rhesus monkey oocytes in chemically defined cultured media and their functional assessment by IVF and embryo development. Hum Reprod 2001; 16:300-5.

14. Cortvrindt RG, Hu Y, Liu J, Smitz JE. Timed analysis of the nuclear maturation of oocytes in early preantral mouse follicle culture supplemented with recombinant gonadotropin. Fertil Steril 1998; 70:1114-25.
15. Dell'Aquila ME, Cho YS, Minoia P, Traina V, Lacalandra GM, Maritato F. Effects of follicular fluid supplementation of in-vitro maturation medium on the fertilization and development of equine oocytes after in-vitro fertilization or intracytoplasmic sperm injection. Hum Reprod 1997; 12:2766-72.

16. Mikkelsen AL, Smith S, Lindenberg S. Possible factors affecting the development of oocytes in invitro maturation. Hum Reprod 2000; 15:11-7.

17. Mikkelsen AL, Andersson AM, Skakkebaek NE, Lindenberg S. Basal concentrations of oestradiol may predict the outcome of in-vitro maturation in regularly menstruating women. Hum Reprod 2001; 16:862-7.

18.Licciardi FL, Liu HC, Rosenwaks Z. Day 3 oestradiol serum concentration as prognosticators of ovarian stimulation response and pregnancy outcome in patients undergoing in vitro fertilization. Fertil Steril 1995; 64:991-4.

19.Wu J, Zhang L, Wang X. Maturation and apoptosis of human oocytes in vitro are age-related. Fertil Steril 2000; 74:1137-41.

20.Kodama H, Fukuda J, Karube H, Matsui T, Shimizu Y, Tanaka T. High incidence of embryo transfer cancellations in patients with polycystic ovarian syndrome. Hum Reprod 1995; 10:1962-7.

21.Cha KY, Han SY, Chung HM, et al. Pregnancies and deliveries after in vitro maturation culture followed by in vitro fertilization and embryo transfer without stimulation in women with polycystic ovary syndrome. Fertil Steril 2000; 73:978-83.

22. Organização Mundial da Saúde. Manual de laboratório para o exame do sêmen humano e interação esperma-muco cervical. $1^{\text {a }}$ ed. São Paulo: Santos; 1994. p.111.

23. Van Steirteghem A, Nagy P, Joris H, et al. The development of intracytoplasmic sperm injection. Hum Reprod 1996; 11 Suppl 1:59-72.

24.Smith SD, Mikkelsen AL, Lindenberg S. Development of human oocytes matured in vitro for 28 or 36 hours. Fertil Steril 2000; 73:541-4.

Recebido em: 25/3/2003 Aceito com modificações em: 12/8/2003

\section{RBGO}

Éumapab] icaçãodaFHBHAstoqueaceitaartigosprovenientes

ceginecologistas, dostetraseckatrasespecialidackes.

PORIUANTO, PUBTIQUE ! ! !

Mende jáseuartigopara FBt) 